OPEN ACCESS

Edited by:

Andrew J. Lewis,

Murdoch University, Australia

Reviewed by:

Ruben David Baler,

National Institutes of Health $(\mathrm{NIH})$,

United States

Alessio Simonetti,

Baylor College of Medicine,

United States

*Correspondence:

You Zhou

youz7@student.unimelb.edu.au

tThese authors have contributed equally to this work

Specialty section:

This article was submitted to Addictive Disorders,

a section of the journal

Frontiers in Psychiatry

Received: 01 November 2018 Accepted: 16 May 2019

Published: 12 June 2019

Citation:

Yang C, Zhou Y, Cao Q,

$X i a M$ and $A n J$ (2019)

The Relationship Between

Self-Control and Self-Efficacy

Among Patients With Substance

Use Disorders: Resilience and

Self-Esteem as Mediators.

Front. Psychiatry 10:388.

doi: 10.3389/fpsyt.2019.00388

\section{The Relationship Between Self-Control and Self-Efficacy Among Patients With Substance Use Disorders: Resilience and Self-Esteem as Mediators}

\author{
Chunyu Yang 1,2t, You Zhou ${ }^{3 *}$, Qilong Cao ${ }^{2,4 \dagger}$, Mengfan $\mathrm{Xia}^{2}$ and Jing An ${ }^{1,2}$ \\ ${ }^{1}$ School of Economics and Management, Changzhou Institute of Technology, Changzhou, China, ${ }^{2}$ School of Social and \\ Behavioral Sciences, Nanjing University, Nanjing, China, ${ }^{3}$ Graduate School of Humanities and Social Sciences, University of \\ Melbourne, Melbourne, VIC, Australia, ${ }^{4}$ Business School, Changzhou University, Changzhou, China
}

Background: While substance use disorder is one of the overarching health and social issues that might seriously disrupt individuals' self-control and self-efficacy, most previous studies have been conducted among university students or other groups, and little is known about how the underlying mechanisms between self-control and self-efficacy might impact patients with substance use disorders.

Objectives: The purpose of this study is to investigate how resilience and self-esteem mediate the relationships between self-control and self-efficacy among patients with substance use disorders.

Methods: We conducted a cross-sectional study of 298 patients with substance use disorder from Shifosi rehab in China. Diagnostic and Statistical Manual of Mental Disorders (5th Edition)-based diagnostic questionnaires were used to collect demographic information and assess addiction severity. The Dual-Modes of Self-Control Scale (DMSC-S) was implemented to measure self-control, while self-esteem was measured using the Self-esteem Scale (SES). The Connor-Davidson Resilience Scale (CD-RISC) was used to measure resilience, and selfefficacy was measured by the regulatory emotional self-efficacy scale (RESE).

Results: The correlations between all the dimensions and total scores on the self-control, resilience, self-esteem, and self-efficacy were significantly positive $(p<0.01)$, indicating that they could predict patients' self-efficacy. Bootstrap testing indicated that resilience and self-esteem fully mediated the relationship between self-control and self-efficacy, relationships between self-control and self-esteem were partially mediated by resilience, and resilience partially mediated the relationship between self-esteem and self-efficacy. Finally, the multiple-group analysis indicated that the relationships among self-control, resilience, self-esteem, and self-efficiency did not differ with respect to gender.

Conclusions: The path from self-control through resilience and self-esteem and on to self-efficacy is significant among patients with substance use disorders, suggesting that increasing self-control, resilience, and self-esteem can improve self-efficacy among patients with substance use disorders.

Keywords: self-control, resilience, self-esteem, self-efficacy, patients with substance use disorders 


\section{INTRODUCTION}

Substance use disorder is among the overarching health and social issues that could alter both psychological states and neural mechanisms (1-3), and a wide range of studies has suggested that illicit drug use might disrupt individuals' selfcontrol and self-efficacy capabilities (4-7). Although extensive studies have examined the relationships between self-control and self-efficacy (8-11), it is still complicated to draw general and incontestable conclusions about the complex relationships between self-control and self-efficacy, and one primary reason for this is that self-control and self-efficacy are both susceptible to situational factors $(12,13)$. In addition, since most correlational studies of such relationships have been conducted among university students or other groups $(8,10,14)$, and few have dealt with patients with substance use disorder, it seems worthwhile to evaluate potential relationships between self-control and self-efficacy among patients suffering from such disorders.

\section{Self-Control and Self-Efficacy}

Self-control is now widely conceptualized as a self-initiated ability that enables individuals to resist inappropriate or selfdestructive temptations to achieve long-term goals. Historically, the definition of self-control has been developed from the concept of "effortful control" to the concept of "pursuing enduringly valued goals" (15). People with higher levels of selfcontrol are more inclined to delay personal gratification based on instant impulses and allocate more well-resource energy to their future goals. At the same time, self-control is susceptible to various situational factors, including substance use disorders (13), family cohesion (16), and peer norms (17), and self-control has also been found to be closely correlated with a wide range of behaviors like psychological well-being $(18,19)$, academic performance $(20,21)$, and pathology $(22,23)$.

Self-efficacy plays a crucial role in forming self-judgment about whether one could realize intended goals. Self-efficacy can be separated into two types: general self-efficacy and task-specific self-efficacy. According to Bandura (12), general efficacy refers to an individual's ability to perform across various situations, while task-specific self-efficacy is related to an individual's ability to perform in a specific situation (that study assessed general selfefficacy). Many studies have suggested that people with high selfefficacy are more likely to be confident in coping with and handling resource-demanding tasks (24-26). According to Bandura (12), self-efficacy develops through individuals' interactions with their surroundings because they are increasingly familiar with their ability to overcome tough tasks. The more demanding a task is, the less self-efficacy individuals may have, and they may then be less likely to engage in the task (27). Some studies also suggest that self-efficacy is closely associated with physical and mental health $(25,28)$, academic performance $(29)$, and employment skills (30).

A large proportion of studies insist that self-control is positively correlated with self-efficacy $(9,10)$, and Bandura (31) suggested that self-control also plays a significant role in promoting self-efficacy. One interpretation of this underlying mechanism is that, on one hand, people with high self-control tend to pay more attention to their intended goals, while on the other hand, individuals with higher self-control are more likely to possess stable self-efficacy with respect to future tasks because they have successfully overcome similar hurdles in the past. Conversely, some studies have revealed that under specific circumstances self-control is negatively associated with self-efficacy $(8,32)$. EinGar and Steinhart (8) revealed that people with low self-control might show higher self-efficacy when confronted with distantfuture tasks. They may procrastinate not because of a failure in self-control, but because they have experienced sufficiently high self-efficacy before the task deadline. However, there is no general and incontestable finding as to the relationship between self-control and self-efficacy because both traits are susceptible to situational factors $(12,13)$.

Substance dependence can be a remarkable situational factor not only because it might alter individuals' psychological states, but also it may modify their neural mechanisms. Numerous studies have suggested that consuming illicit drugs would most likely disrupt individuals' self-control and self-efficacy capabilities (4-7), and many studies have verified that illicit drugs often lead to structural changes within specific brain regions, such as the prefrontal cortex (2) that modulates capabilities of balancing self-interests and aligning actions with internal goals (33), and those capabilities are the major components of selfcontrol (15). Given the occurrence of psychological and physical alterations, while there might be heterogeneity between patients with substance use disorder and other groups with respect to analyzing relationships between these two traits, less attention has been given to examining the potential association between self-control and self-efficacy among patients with substance use disorder. To fill in this gap, this study integrated resilience and self-esteem as mediators to further analyze underlying mechanisms between self-control and self-efficacy among patients with substance use disorders.

\section{Resilience and Self-Esteem as Mediators}

One specific mediator is resilience, defined as the ability to adapt to stress and negative emotions (34). Although few researchers have focused on the role of resilience in mediating between self-control and self-efficacy, there are numerous studies committed to exploring associations between self-control and resilience $(35,36)$, and association between resilience and self-efficacy (37-39). The findings of those studies showed that patients with higher levels of self-control are more likely to exhibit greater resilience than those with lower self-control $(35,40)$. Self-control acts as a protective factor to reduce the possibilities of feeling ashamed by providing resistance to temptation by inappropriate impulsion. It has been proven that shameful feelings are negatively correlated with resilience $(41,42)$, and there are many studies suggesting that resilience may predict self-efficacy. According to Schwarzer and Warner (43), adolescents with higher resilience are more likely to feel confident and be more effective and efficient in completing tasks, especially in high-effort situations. 
Self-esteem serves as another mediator between selfcontrol and self-efficacy by reflecting the evaluation made by individuals regarding their own worth (44). Extant research indicates that people with higher self-control tend to exhibit higher levels of self-esteem than those with lower levels of selfcontrol $(22,45)$. Self-control might also contribute to various types of positive outcomes that act as indicators of self-esteem, such as better academic grades (46), better psychological adjustment (22), and better interpersonal relationships (47). Many other studies have also shown that self-esteem demonstrates the potential for fostering self-efficacy $(48,49)$ by providing self-confidence, regarded as a crucial component of self-efficacy (50).

Still, other studies have also identified close correlation between resilience and self-esteem. For example, Benetti and Kambouropoulos (51) published a study suggesting that resilience exerts a positive impact on self-esteem via a positive affect. Based on the fact that there are numerous studies evaluating the correlational roles of resilience and self-esteem, it seemed favorable for this study to select resilience and selfesteem as mediators between self-control and self-efficacy.

\section{The Present Study}

There are numerous studies suggested that self-esteem and resilience have close links with self-control and self-efficacy (10, 22, 43, 45). Moreover, based on previous studies, a multiplemediator model is more comprehensive than a single-mediator model with respect to conceptualizing the intermediary mechanisms $(52,53)$. In this study, we hypothesized resilience and self-esteem as mediators in the relationships between selfcontrol and self-efficacy among patients with substance use disorder. Specifically, substance dependents with high selfcontrol might ultimately experience higher levels of resilience and self-esteem to promote the functioning of self-efficacy. The detailed hypothesized model is presented in Figure $\mathbf{1}$.

\section{METHOD}

\section{Participants and Procedure}

The study was conducted at Shifosi Rehabilitation Center, a compulsory detoxification center, and involved 298 Chinese participants who had experienced substance use disorders. The Ethics Committee of Nanjing Medical University approved the study to ensure that it fully considered human rights, ethics, and safety throughout the procedures, and all participants signed informed-consent documents prior to the initiation of the assessment. To ensure confidentiality of the whole study, participants were separately placed in a separate conference room while completing the questionnaires in about $30 \mathrm{~min}$.

The study dealt with seven socio-demographic characteristics of the participants: age, gender, education level, work status, years of use, substance classification, and DSM-5 addiction severity criteria. Inclusion criteria included the following: were of age of 18 years or more, exhibited normal and stable cognitive states, had been diagnosed with substance use disorders within the last 12 months, had normal vision and color perception, were right-handed, and had voluntarily agreed to participant in the study. Exclusion criteria included the following: a history of serious heart, liver, or kidney illnesses, cognitive disabilities, or psychiatric impairment caused by functional factors (e.g., physical illness, dysfunctions of neuroactive substance). The collective socio-demographic characteristics of the 298 participants are shown in Table $\mathbf{1}$.

The substance classes examined in the present study were matched with the drug classification of DSM-5 (54). Since some of the participants were polysubstance users (using more than one illicit substance), the sum of the prevalence with respect to drug classes exceeded $100 \%$. As shown in Table 1, there were six drug classes: heroin (27.5\%), methamphetamine (84.9\%), ketamine (17.8\%), methyenedioxymethamphetamine (MDMA)/ ecstasy $(9.7 \%)$, marihuana (11.1\%), and others $(2.7 \%)$.

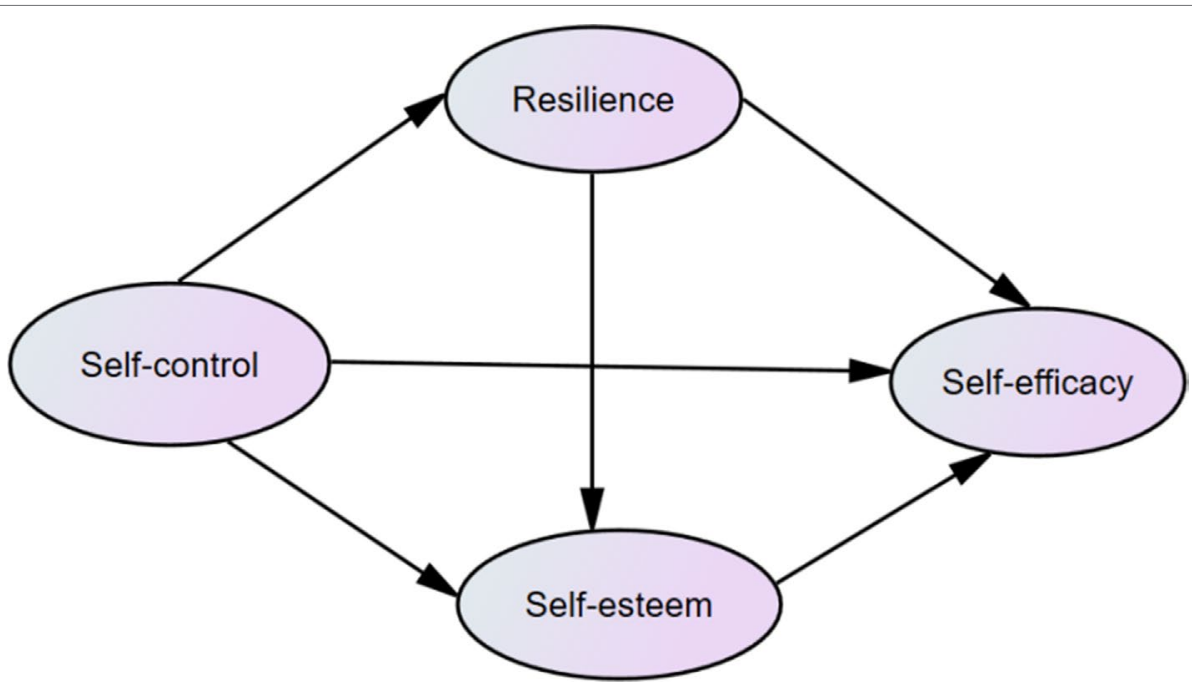

FIGURE 1 | The hypothesized model concerning the relationship between self-control and self-efficiency: resilience and self-esteem as mediators. 
TABLE 1 | Sample characteristics.

\begin{tabular}{|c|c|c|c|c|c|c|c|}
\hline \multirow[t]{2}{*}{ Sample characteristics } & & \multicolumn{2}{|c|}{ Total $(\mathbf{N}=\mathbf{2 9 8})$} & \multicolumn{2}{|c|}{ Male } & \multicolumn{2}{|c|}{ Female } \\
\hline & & $\mathbf{M}$ & SD & $\mathbf{n}$ & $\%$ & $\mathbf{n}$ & $\%$ \\
\hline \multirow[t]{3}{*}{ Age } & Male (18-64) & 37.5 & 9.5 & - & - & - & - \\
\hline & Female (19-55) & 35.2 & 8.2 & - & - & - & - \\
\hline & & $\mathbf{n}$ & $\%$ & & & & \\
\hline \multirow[t]{2}{*}{ Gender } & 1. Male & 210 & 70.5 & - & - & - & - \\
\hline & 2. Female & 88 & 29.5 & - & - & - & - \\
\hline \multirow[t]{5}{*}{ Education level: ( $n=293$ ) } & 1. Elementary school and below & 49 & 16.4 & 35 & 16.7 & 14 & 15.9 \\
\hline & 2. Middle school & 125 & 41.9 & 87 & 41.4 & 38 & 43.2 \\
\hline & 3. High school & 88 & 29.5 & 61 & 29.0 & 26 & 29.5 \\
\hline & 4. College & 29 & 9.7 & 20 & 9.5 & 9 & 10.2 \\
\hline & 5. Above college & 2 & 0.7 & 2 & 1.0 & 0 & 0.0 \\
\hline \multirow[t]{3}{*}{ Work status: $(n=289)$} & 1. Unemployment & 136 & 45.6 & 88 & 41.9 & 48 & 54.5 \\
\hline & 2. Employment & 134 & 45.0 & 108 & 51.4 & 25 & 28.4 \\
\hline & 3. Others & 19 & 6.4 & 11 & 5.2 & 8 & 9.1 \\
\hline \multirow{3}{*}{$\begin{array}{l}\text { Years of substance use: } \\
(n=271)\end{array}$} & $<5$ years & 85 & 28.5 & 66 & 31.4 & 19 & 21.6 \\
\hline & $6-10$ years & 94 & 31.5 & 62 & 29.5 & 32 & 36.4 \\
\hline & $>10$ years & 91 & 30.5 & 57 & 27.1 & 34 & 38.6 \\
\hline \multirow[t]{6}{*}{ Substance Classification } & 1. Heroin & 82 & 27.5 & 60 & 28.6 & 22 & 25.0 \\
\hline & 2. Methamphetamine & 253 & 84.9 & 172 & 81.9 & 81 & 92.0 \\
\hline & 3. Ketamine & 53 & 17.8 & 30 & 14.3 & 23 & 26.1 \\
\hline & 4. MDMA (ecstasy) & 29 & 9.7 & 18 & 8.6 & 11 & 12.5 \\
\hline & 5. Marihuana & 33 & 11.1 & 19 & 9.0 & 14 & 15.9 \\
\hline & 6. Others & 8 & 2.7 & 6 & 2.9 & 2 & 2.3 \\
\hline \multirow[t]{3}{*}{ Addiction severity } & Mild & 2 & 0.67 & 2 & 1.0 & 0 & 0.0 \\
\hline & Moderate & 5 & 1.68 & 4 & 1.9 & 1 & 1.1 \\
\hline & Severe & 291 & 97.65 & 204 & 97.1 & 87 & 98.9 \\
\hline
\end{tabular}

The DSM-5 lists the following 11 symptoms of substance use disorders for assessing addiction severity: hazardous use, craving, withdrawal, tolerance, prolonged use of substantial amounts, collapse of relational and social relationships, withdrawal from social and occupational activities, use-related physical/ psychological issues, substantial time spent using, repeated attempts to quit/control use, and social/interpersonal issues related to use (54). In DSM-5, addiction severity is measured by a criteria count: mild (from 2 to 3 criteria), moderate (from 4 to 5 criteria), and severe (from 6 to 11 criteria). The assessments were conducted using a diagnostic questionnaire that merged 11 DSM-5 criteria, and 291 of the participants (97.65\%) were designated with the severest level of substance use disorders, while only 5 participants (1.68\%) and $2(0.67 \%)$, respectively, of the participants, were designated with moderate level and mild level disorders. The vast majority of patients were diagnosed with severe level of addiction because they were being treated in a mandatory drug treatment center that mainly tends to hospitalize patients with chronic substance use disorders.

\section{Measures}

The study used a diagnostic questionnaire to acquire demographic information and assess the participants' addiction severity levels. In the questionnaire, the participants self-reported demographic information such as gender, age, education level, and work status. The diagnostic questionnaire included three parts related to assessing addiction severity: substance use history, substance use behavior, and consequences and intervention history related to substance use. The diagnosis was based on 11 DSM-5 criteria.
Finally, addiction severity was measured by counting the number of criteria matched in the questionnaires, resulting in a Cronbach's a coefficient of 0.70 .

The Dual-Modes of Self-Control Scale (DMSC-S) was administered to assess participants' levels of self-control. The scale consists of 21 items with responses on a five-point Likert scale from 1 = "not at all true" to 5 = "very true" (55). The DMSC-S is assessed using the impulse system and control system subscales. The impulse system subscale includes three factors: impulsive, easy distraction, and delay gratification, and the control system subscale includes two factors: problem-solving and future time view. The higher the score on the impulse system subscale, the stronger the factors of impulsiveness, distraction, and delay gratification, and the weaker the self-control ability. The higher the score in the control system subscale, the more likely the problem is solved satisfactorily, the stronger the future time view, and the stronger the self-control. The Cronbach's a coefficient in our study was 0.901 .

The Connor-Davidson Resilience Scale (CD-RISC25) (56) was administered to assess participant resilience. The CD-RISC consists of 25 items with responses given using a five-point Likert scale from $0=$ "not true at all" to $4=$ "true nearly all of the time" (57). The total scores ranged from 0 to 100 . The scale consists of three factors, viz., toughness, strength, and optimism, and the higher the score, the higher the resilience and the easier for an individual to recover when a stressful time is experienced. The Cronbach's a coefficient in our study was 0.939 .

To assess participant self-esteem, we administered the Rosenberg Self-Esteem Scale (RSES) (58), designed to assess an individual's overall perception of self-worth and self-acceptance. 
The RSES consists of 10 items, scored at four levels, with a total score of 10-40 points (59). The higher the score, the higher the degree of self-esteem. The scale includes items such as, "I feel that I am a valuable person, at least on the same level as others" and "I feel that I have many good qualities." The Cronbach's a coefficient in our study was 0.711 .

The Chinese version of the Regulatory Emotional Self-Efficacy Scale (RESS) was used to assess each participant's evaluation of their ability to manage their emotions (60). This scale has two dimensions: perceived self-efficacy in expressing positive emotion and perceived self-efficacy in managing negative emotion (61). RESE consists of 17 items (e.g., "When the happy things happen, I will express my pleasure"), with responses using a five-point score ranging from 1 (completely disagree) to 5 (completely agree). The Cronbach's a coefficient in our study was 0.895 .

\section{Data Analysis}

We used initial correlational analysis to examine the relationships between self-control, resilience, self-esteem, and self-efficacy. Descriptive statistics and means and standard deviations (SD) were tested via IBM SPSS Statistics version 22.

In accordance with Anderson and Gerbing (62), we performed a two-step procedure to analyze mediation effects. We first used a measurement model that contained four potential variables: self-control, resilience, self-esteem, and self-efficacy, to test whether each latent variable could be well-represented by its indicators. We next determined whether the results from the measurement model were satisfactory; the structural model could be tested using maximum likelihood (ML) estimation in the AMOS 24.0 program. To control inflation of measurement errors generated by multiple items for the latent variable, we created several parcels using a random assignment method (63), and specially created three-item parcels for resilience and self-esteem, two-item parcels for self-control, and five-item parcels for self-efficacy.

To assess the adequacy of model fit, we used the following eight goodness-of-fit indices $(64,65): 1)$ chi-square statistics between 1 and $3 ; 2$ ) a standardized root mean square residual (SRMR) of 0.06 or less; 3) a root-mean-square error of approximation (RMSEA) of 0.08 or less; 4) a goodness-of-fit index (GFI) of 0.90 or higher; 5) a Tucker-Lewis Index (TLI) of 0.90 or higher; 6) a comparative fit index (CFI) of 0.90 or higher; 7) Akaike information criterion (AIC); and 8) an expected cross-validation index (ECVI). We also used AIC and ECVI to compare two or more models, with a smaller value of AIC representing the better fit to the hypothesized model (66) and a smaller value of ECVI indicating a more significant potential for replication (67).

\section{RESULTS}

\section{Preliminary Analyses}

The descriptive statistics including mean, SD, alpha, reliability estimates (Cronbach's alpha coefficients), and correlations for all the study variables and clinical variables are shown in Table 2. They showed that, with respect to the clinical variables, there were significant negative correlations of age with gender, education level, and self-esteem, with gender on work status, and with work status on addiction severity, while there were significant positive correlations of age with years of addiction, with gender on addiction severity, self-control, and self-esteem, with education level on work status and self-efficiency, and with years of addiction on addiction severity. Moreover, all correlations among self-control, resilience, self-esteem, and self-efficiency were proven to be statistically significant $(\mathrm{p}<0.01)$.

\section{Measurement Model}

The measurement model included 4 latent factors: self-control, resilience, self-esteem, and self-efficacy, and 13 observed variables. Although the initial estimate was unsatisfactory, a revised model reflected satisfactory data: $\left(\chi^{2}=156.67, \mathrm{df}=\right.$ $54, \chi^{2} / \mathrm{df}=2.901, \mathrm{p}<0.001 ;$ SRMR $=0.0495 ;$ RMSEA $=0.080$; $\mathrm{GFI}=0.927$; $\mathrm{TLI}=0.922 ; \mathrm{CFI}=0.946$, and $\mathrm{ACI}=256.667 \mathrm{ECVI}=$ $0.864, \mathrm{CFA})$. All latent variable factor loadings were reliable $(\mathrm{p}<0.01)$, and fitting results show that all latent variables could be well represented by the respective indicators.

TABLE 2 | Means, standard deviations (SD), Alpha, reliabilities, and intercorrelations among study variables.

\begin{tabular}{|c|c|c|c|c|c|c|c|c|c|c|c|c|c|}
\hline Measure & Mean & SD & $\alpha$ & 1 & 2 & 3 & 4 & 5 & 6 & 7 & 8 & 9 & 10 \\
\hline Age & 36.8 & 9.17 & - & 1 & & & & & & & & & \\
\hline Gendera & - & - & - & $-0.116^{\star}$ & 1 & & & & & & & & \\
\hline Education level & - & - & - & $-0.135^{\star}$ & -0.005 & 1 & & & & & & & \\
\hline Work status & - & - & - & -0.026 & $-0.153^{\star \star}$ & $0.122^{\star \star}$ & 1 & & & & & & \\
\hline Years of addict & 10.3 & 7.71 & - & $0.594^{\star \star}$ & 0.087 & -0.085 & -0.110 & 1 & & & & & \\
\hline Addiction severity & 9.71 & 1.61 & 0.70 & -0.048 & $0.220^{\star \star}$ & 0.056 & $-0.209^{\star \star}$ & $0.282^{\star \star}$ & 1 & & & & \\
\hline Self-control & 65.87 & 8.04 & 0.901 & 0.022 & $0.149^{\star \star}$ & 0.061 & 0.109 & -0.021 & 0.042 & 1 & & & \\
\hline Resilience & 82.27 & 17.62 & 0.939 & 0.020 & 0.059 & 0.034 & 0.047 & -0.037 & 0.079 & $0.160^{\star \star}$ & 1 & & \\
\hline Self-esteem & 25.79 & 2.74 & 0.711 & $-0.130^{\star}$ & $0.156^{\star \star}$ & 0.032 & 0.068 & 0.037 & -0.104 & $0.292^{\star \star}$ & $0.184^{\star \star}$ & 1 & \\
\hline Self-efficacy & 56.58 & 11.75 & 0.895 & 0.018 & 0.058 & $0.129^{\star}$ & 0.035 & 0.038 & 0.054 & $0.171^{\star \star}$ & $0.481^{\star \star}$ & $0.231^{\star *}$ & 1 \\
\hline
\end{tabular}

$\alpha=$ Cronbach's alpha.

${ }^{*}$ Correlation is significant at the 0.05 level (two-tailed).

${ }^{*}$ Correlation is significant at the 0.01 level (two-tailed).

${ }^{a}$ Gender is coded $1=$ male, 2 = female. 


\section{Structural Model}

Without mediators, the direct path from self-control (the predictor) to self-efficacy (the criterion, $\mathrm{r}=0.171, \mathrm{p}<0.01$ ) was significant. We first built a fully mediated model (Model 1) containing two mediator variables (resilience and self-esteem) without a direct path from self-control to self-efficacy. While the initial results were unsatisfactory, a revised model produced satisfactory results [NC $(\chi 2 / \mathrm{df})=2.751, \mathrm{RMSEA}=0.077, \mathrm{SRMR}=0.0561, \mathrm{GFI}=0.924$, $\mathrm{TLI}=0.912, \mathrm{CFI}=0.931$, and $\mathrm{AIC}=250.070]$, and all standardized path coefficients were significant (Table 2). Next, based on results from Model 1, a partially mediated model (Model 2) was tested by adding a direct path from self-control to self-efficacy, producing satisfactory test results: $\mathrm{NC}(\chi 2 / \mathrm{df})=2.780, \mathrm{RMSEA}=0.077$, $\mathrm{SRMR}=0.0563, \mathrm{GFI}=0.925, \mathrm{TLI}=0.911, \mathrm{CFI}=0.937$, and Akaike information criterion $(\mathrm{AIC})=250.882$, although the standardized path coefficient from self-control to self-efficacy in Model 2 was not significant. With respect to goodness-of-fit indices, while there was no noticeable difference between Model 1 and Model 2, there was one standardized path coefficient that was not significant in Model 2, so Model 1 was found to be better than Model 2. Next, in order to test the distal mediation effect, based on Model 1, a path from resilience to self-esteem (Model 3) was added to the model, with test results showing that, with respect to goodness-offit indices, while there was little difference between Model 1 and Model 3, the AIC and ECVI indices in Model 3 were smaller than for Model 1, indicating that Model 3 was better than Model 1 .

To further explain the mediating model, we built Model 4 that reversed the paths among self-efficacy, self-esteem, and resilience by controlling self-control (i.e., from self-efficacy to self-control and resilience followed by self-esteem to resilience), to test an alternative causal hypothesis. Although nearly all indices in Model 4 were inconsistent with the data, the GFI and CFI values were greater than $0.900\left[\left(\mathrm{NC} \chi^{2} / \mathrm{df}\right)=3.565, \mathrm{RMSEA}=0.093, \mathrm{SRMR}=0.1067\right.$, $\mathrm{GFI}=0.908$, TLI $=0.872, \mathrm{CFI}=0.909$, and $\mathrm{AIC}=268.054]$, and the standardized path coefficients between self-esteem and resilience were not significant in Model 4. In addition, the indices of AIC and ECVI in Model 3 were smaller than those from Model 4, so Model 3 was chosen as the most suitable model for evaluating the mediating effects (Table 3). The final structure model is shown in Figure 2.

We used the bootstrapping procedures method of AMOS24.0 to test the significance of the mediated models. Based on recommendations of MacKinnon et al. (68), we generated 10,000 samples by random sampling of the original dataset $(\mathrm{N}=426)$. If the $95 \%$ confidence interval for the outcome of the mediation effect did not contain zero, the mediation effect would be significant at the 0.05 level, and Table 4 shows the indirect effects and their associated $95 \%$ confidence intervals, revealing that selfesteem and resilience exerted significant indirect effects on selfcontrol and self-efficacy.

\section{Gender Differences}

There was no statistically significant gender difference in terms of self-efficacy, resilience, and self-esteem, although females scored higher than males with respect to self-control.

To further examine gender differences in the intermediary model, we conducted a multigroup analysis to explore whether the path coefficients differed significantly for males and females. According to Byrne (69), we compared gender difference using the following two models: 1) an unconstrained model, allowing all the paths to vary across both male and female groups; and 2) a constrained model, constraining all the parameters, including factor loading, error variances, and structure covariance, to be equal across male and female groups. After confirming the moderating effect of gender, we examined mediating models for males and

TABLE 3 | Fit indices among competing models.

\begin{tabular}{|c|c|c|c|c|c|}
\hline Regression weights & Model1 & Model2 & Model3 & Model4 & Target value \\
\hline Self-control $\rightarrow$ Self-efficacy & & 0.142 & & & \\
\hline Self-control $\rightarrow$ Self-esteem & $0.558^{\star \star \star}$ & $0.546^{\star \star \star}$ & $0.315^{\star}$ & $0.352^{\star \star \star}$ & \\
\hline Self-esteem $\rightarrow$ Self-efficacy & $0.304^{\star \star}$ & $0.250^{\star}$ & $0.303^{\star \star}$ & & \\
\hline Self-control $\rightarrow$ Resilience & $0.719^{\star \star \star}$ & $0.715^{\star \star \star}$ & $0.679^{\star \star \star}$ & $0.525^{\star \star \star}$ & \\
\hline Resilience $\rightarrow$ Self-efficacy & $0.434^{\star \star \star}$ & $0.352^{\star \star}$ & $0.421^{\star \star \star}$ & & \\
\hline Self-esteem $\rightarrow$ Resilience & & & & 0.103 & \\
\hline Resilience $\rightarrow$ Self-esteem & & & $0.190 *$ & & \\
\hline Self-efficacy $\rightarrow$ Resilience & & & & $0.366^{\star \star \star}$ & \\
\hline Self-efficacy $\rightarrow$ Self-esteem & & & & $0.384^{\star \star \star}$ & \\
\hline$\chi^{2}$ & 154.070 & 152.882 & 149.968 & 196.054 & \\
\hline df & 56 & 55 & 55 & 55 & \\
\hline$\chi^{2 / d f}$ & 2.751 & 2.780 & 2.727 & 3.565 & \\
\hline SRMR & 0.0561 & 0.0563 & 0.0539 & 0.1067 & $<0.06$ \\
\hline RMSEA & 0.077 & 0.077 & 0.076 & 0.093 & $<0.08$ \\
\hline GFI & 0.924 & 0.925 & 0.926 & 0.908 & $>0.90$ \\
\hline TLI & 0.912 & 0.911 & 0.914 & 0.872 & $>0.90$ \\
\hline CFI & 0.937 & 0.937 & 0.939 & 0.909 & $>0.90$ \\
\hline $\mathrm{AIC}$ & 250.070 & 250.882 & 221.968 & 268.054 & \\
\hline ECVI & 0.842 & 0.845 & 0.747 & 0.903 & \\
\hline
\end{tabular}

*Correlation is significant at the 0.05 level (two-tailed).

${ }^{* *}$ Correlation is significant at the 0.01 level (two-tailed).

${ }^{* * *}$ Correlation is significant at the 0.001 level (two-tailed). 


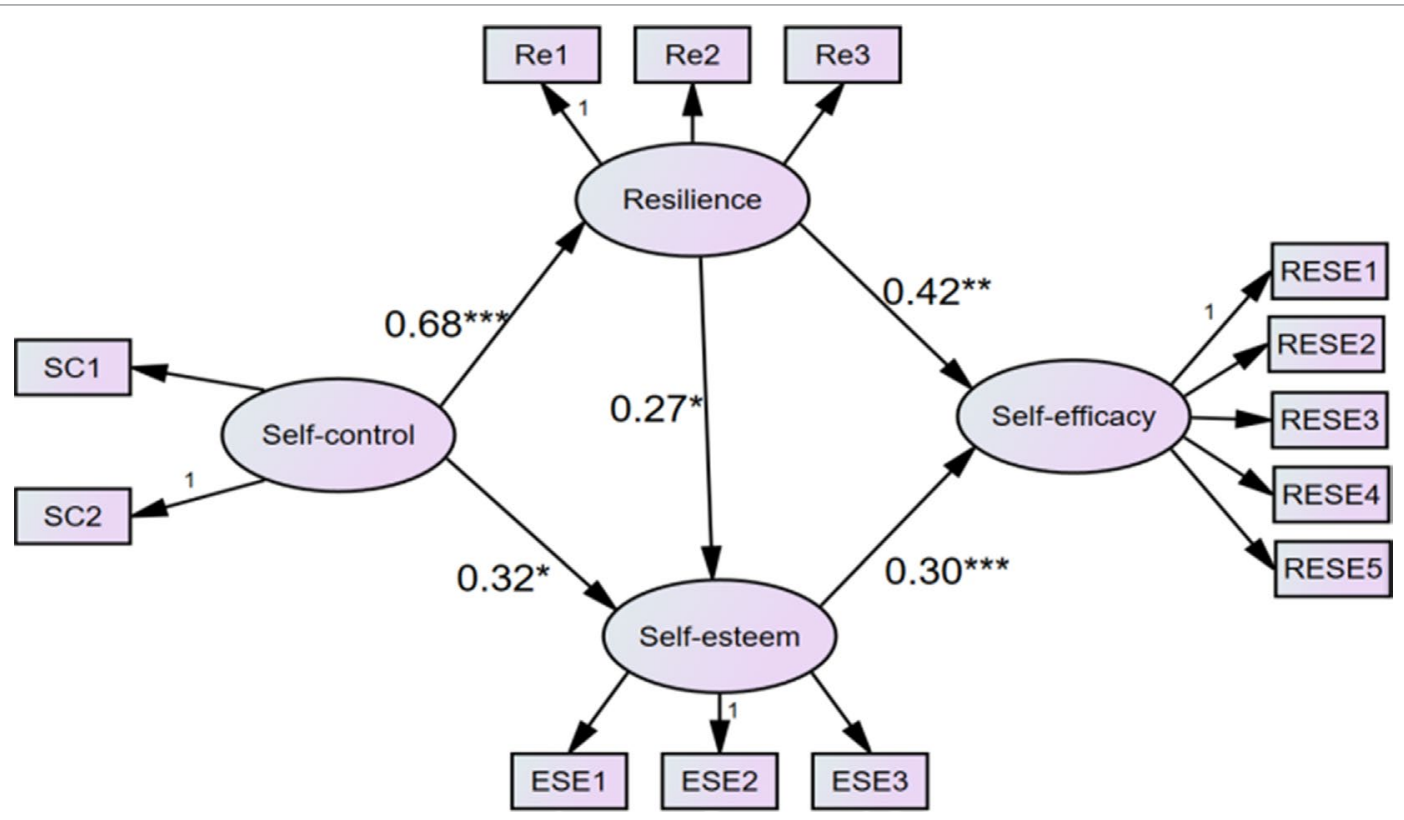

FIGURE 2 | The finalized structural model $(\mathrm{N}=298)$ in the present study. Note. Factor loading is standardized. SC1-SC2 = Two parcels of self-control; Re1-Re3 = Three parcels of Resilience; ESE1-ESE3 = Three parcels of Self-esteem. RESE1-RESE5 = Five parcels of regulatory emotional self-efficacy.

TABLE 4 | Bootstrapping indirect effects and 95\% confidence intervals (Cl) for the final mediational model.

\begin{tabular}{|c|c|c|c|c|}
\hline \multirow[t]{2}{*}{ Number } & \multirow[t]{2}{*}{ Model pathways } & \multirow{2}{*}{$\begin{array}{c}\text { Point estimates } \\
\boldsymbol{\beta}\end{array}$} & \multicolumn{2}{|c|}{$95 \% \mathrm{Cl}$} \\
\hline & & & Lower & Upper \\
\hline 1 & Self-control $\rightarrow$ Resilience $\rightarrow$ Self-efficacy & 0.1046 & 0.0346 & 0.1902 \\
\hline 2 & Self-control $\rightarrow$ Self-esteem $\rightarrow$ Self-efficacy & 0.0516 & 0.0146 & 0.1050 \\
\hline 3 & Self-control $\rightarrow$ Resilience $\rightarrow$ Self-esteem $\rightarrow$ Self-efficacy & 0.0043 & 0.0009 & 0.0132 \\
\hline 4 & Self-control $\rightarrow$ Resilience $\rightarrow$ Self-esteem & 0.0920 & 0.0546 & 0.1294 \\
\hline 5 & Resilience $\rightarrow$ self-esteem $\rightarrow$ Self-efficacy & 0.0181 & 0.0061 & 0.0389 \\
\hline
\end{tabular}

females separately, with results indicating that differences between these two models were not significant $\left[\Delta \chi^{2}(18)=26.480, \mathrm{p}=\right.$ 0.089]. Furthermore, in accordance with Arbuckle (70), we used the critical ratios of differences (CRDs) to judge the difference between two parameter estimates, measured by dividing the difference between two estimates by an estimate of the standard error of the difference. If a CRD value is greater than 1.96 (or 2.58), the two parameters were estimated to be significantly different at levels of $\mathrm{p}<0.05$ (or $\mathrm{p}<0.01$ ). Since the CRD analysis in this study indicated no structure path identified as significantly different, the finding indicated that the relationship among self-control, resilience, selfesteem, and self-efficiency did not differ with respect to gender.

\section{DISCUSSION}

Following the methodology of previous literature, in this study, we analyzed the relationship between self-control and self-efficacy among patients with substance use disorder by investigating the mediating role of resilience and self-esteem with respect to the impact of self-control on self-efficacy. The results indicated that self-control is positively related to resilience, self-esteem, and self-efficacy, indicating that our hypothesis is correct.

The mediating impacts of resilience and self-esteem with respect to the relationship between self-control and self-efficacy were identified as significant, with results indicating that participants exhibiting a more positive performance on the self-control scale performed better in terms of resilience and self-efficacy compared with participants exhibiting poorer self-control performance. These results are consistent with those of previous studies that also found resilience to be positively associated with self-control $(36,71)$ and self-efficacy $(43,72)$. Furthermore, participants who performed better in self-control were also identified as achieving more positive performance with respect to self-esteem and self-efficacy, in accordance with previous studies that found self-esteem to be closely correlated with self-control $(22,45)$ and self-efficacy $(48,49)$.

The combined theoretical underpinnings of this study might inform some practical implementations regarding patients' substance use disorders. The theoretical underpinnings of intermediary mechanisms between self-control and self-efficacy 
reflect the idea that success in resisting inappropriate temptations (self-control) might contribute to developing propensity toward enduring pressure or negative emotions (resilience) and achieving greater self-confidence (self-esteem) in ways that enhance chances for individual success in overcoming challenging and resource-demanding tasks (self-efficacy). This suggests that there might be types of practical interventions for enhancing selfefficacy in patients with substance use disorders. For example, interventions might pay closer attention to designing specialized and supervised trait-enhancement programs in ways that provide evidence-based events focusing on fostering traits of self-control, resilience, and self-esteem. Overall, the present findings provide evidence of a psychological process whereby self-control exerts benefits on drug dependents to promote their self-efficacy via improved resilience and self-esteem.

Using the final model of this study, we found that the path "selfcontrol $\rightarrow$ resilience $\rightarrow$ self-esteem $\rightarrow$ self-efficacy" was significant and showed that individuals with higher self-control are prone to experience higher levels of resilience, possibly enhancing their self-esteem and, in turn, producing a greater sense of self-efficacy. For one thing, this path suggests that resilience is a mediator between self-control and self-esteem, agreeing with earlier studies that resilience is significantly associated with self-control (40) and self-esteem (73). This path also demonstrates that self-esteem might act as a mediator between resilience and self-efficacy, an idea consistent with findings that resilience can play a crucial role in promoting self-esteem (74), and self-esteem is closely correlated with self-efficacy (49). Based on these findings, it is reasonable to speculate that resilience might play a mediating role in the relationship between self-control and self-esteem, while selfesteem might act as a mediator between resilience and self-efficacy.

The results of this study also indicated that females experience higher levels of self-control than males. The results related to self-control were in agreement with previous studies suggesting that females tend to regulate themselves better than males (75), probably because the female's prefrontal cortex that dominates the functions of self-control is more active than that of the male (75). However, the final model did not suggest gender differences, rather indicating that both males and females have the same mediating mechanisms between self-control and self-esteem.

In short, the study broadens our horizon with respect to the complicated interplay between self-control, resilience, selfesteem, and self-efficacy among patients with substance use disorder in China. Considering the significant path from selfcontrol through resilience and self-esteem to self-efficacy sheds light on potential mechanisms linking self-control and selfefficacy. This study may also offer valuable evidence on how to organize psychological interventions that aim to promote

\section{REFERENCES}

1. Everitt B. Neural and psychological mechanisms underlying compulsive drug seeking habits and drug memories-indications for novel treatments of addiction. Eur J Neurosci (2014) 40(1):2163-82. doi: 10.1111/ejn.12644

2. George $\mathrm{O}, \mathrm{Koob} \mathrm{G}$. Individual differences in prefrontal cortex function and the transition from drug use to drug dependence. Neurosci Biobehav Rev (2010) 35(2):232-47. doi: 10.1016/j.neubiorev.2010.05.002 self-efficacy of patients with substance use disorders. Encouraging self-control, resilience, and self-esteem in the future would work as proactive tools, helping them enhance self-efficacy.

\section{LIMITATIONS}

This study, like most studies, has some limitations, the main one being the lack of a control group. Also, all the information was collected by questionnaires and scales that can be influenced by subjectivity. Second, to moderate such adverse impacts, it is also recommended that multiple assessment methods such as structured interviews be introduced (SCD-1) to support more in-depth and accurate diagnoses. Third, the diagnostic questionnaire did not cover assessment of histories of comorbid disorders and psychotropic mediation that have been identified as significant variables by many studies of substance use disorders (76, 77). Furthermore, the results were based only on two-dimensional measures of resilience and self-esteem, and in future studies, it might be useful to examine other facets of self-control and explore effects of other possible mediating factors such as social support, affect, and loneliness, on the relationship between self-control and self-efficacy. Finally, the study's sample population's age range was from 18 to 64, so it remains to be seen whether the results could be duplicated with younger or older participants.

\section{ETHICS STATEMENT}

This study was approved by the ethics committee of Nanjing Medical University. All participants volunteered to participate in the study and signed informed consent documents.

\section{AUTHOR CONTRIBUTIONS}

CY, YZ, QC, MX and JA conceived this work. CY conducted the development of the manuscript and contributed to the modeling and data analysis. YZ contributed literature review, discussion, revision and polish. QC, MX and JA revised and finalized the manuscript. All authors read and approved the final manuscript.

\section{FUNDING}

This paper was supported by the Research Fund for Philosophy and Social Science of Universities in Jiangsu Province (2017SJB1800), China Postdoctoral Science Foundation (2018M632285), and Jiangsu Province Social Science Fund Project (18SHC006). 
6. Kadden R, Litt M. The role of self-efficacy in the treatment of substance use disorders. Addict Behav (2011) 36(12):1120-6. doi: 10.1016/j.addbeh. 2011.07.032

7. Weinberg D. Post-humanism, addiction and the loss of self-control: reflections on the missing core in addiction science. Int J Drug Policy (2013) 24(3):173-81. doi: 10.1016/j.drugpo.2013.01.009

8. Ein-Gar D, Steinhart Y. Self-control and task timing shift self-efficacy and influence willingness to engage in effortful tasks. Front Psychol (2017) 1788. doi: 10.3389/fpsyg.2017.01788

9. Gottschling J, Hahn E, Maas H, Spinath F. Explaining the relationship between personality and coping with professional demands: where and why do optimism, self-regulation, and self-efficacy matter? Pers Individ Dif (2016) 100:49-55. doi: 10.1016/j.paid.2016.03.085

10. Graham J, Bray S. Self-control strength depletion reduces self-efficacy and impairs exercise performance. J Sport Exerc Psychol (2015) 37(5):477-88. doi: 10.1123/jsep.2015-0064

11. Iskender $M$. The relationship between self-compassion, self-efficacy, and control belief about learning in Turkish university students. Soc Behav Pers Int J (2009) 37(5):711-20. doi: 10.2224/sbp.2009.37.5.711

12. Bandura A. Self-efficacy: the exercise of control. New York: Freeman (1997).

13. Malouf E, Schaefer K, Witt E, Moore K, Stuewig J, Tangney J. The brief selfcontrol scale predicts jail inmates' recidivism, substance dependence, and post-release adjustment. Pers Soc Psychol Bull (2013) 40(3):334-47. doi: $10.1177 / 0146167213511666$

14. Manavipour D, Saeedian Y. The role of self-compassion and control belief about learning in university students' self-efficacy. J Contextual Behav Sci (2016) 5(2):121-6. doi: 10.1016/j.jcbs.2016.02.003

15. Duckworth A, Gendler T, Gross J. Situational strategies for self-control. Perspect Psychol Sci (2016) 11(1):35-55. doi: 10.1177/1745691615623247

16. Finkenauer C, Buyukcan-Tetik A, Baumeister R, Schoemaker K, Bartels M, Vohs K. Out of control. Curr Direct Psychol Sci (2015) 24(4):261-6. doi: $10.1177 / 0963721415570730$

17. Robinson E, Otten R, Hermans R. Descriptive peer norms, self-control and dietary behaviour in young adults. Psychol Health (2015) 31(1):9-20. doi: 10.1080/08870446.2015.1067705

18. Hofmann W, Luhmann M, Fisher R, Vohs K, Baumeister R. Yes, but are they happy? Effects of trait self-control on affective well-being and life satisfaction. J Pers (2013) 82(4):265-77. doi: 10.1111/jopy.12050

19. Greenaway K, Haslam S, Cruwys T, Branscombe N, Ysseldyk R, Heldreth C. From "we" to "me": group identification enhances perceived personal control with consequences for health and well-being. J Pers Soc Psychol (2015) 109(1):53-74. doi: 10.1037/pspi0000019

20. De Ridder D, Lensvelt-Mulders G, Finkenauer C, Stok F, Baumeister R. Taking stock of self-control. Pers Soc Psychol Rev (2011) 16(1):76-99. doi: $10.1177 / 1088868311418749$

21. Duckworth A, Gross J. Self-control and grit. Curr Direct Psychol Sci (2014) 23(5):319-25. doi: 10.1177/0963721414541462

22. Tangney J, Baumeister R, Boone A. High self-control predicts good adjustment, less pathology, better grades, and interpersonal success. J Pers (2004) 72(2):271-324. doi: 10.1111/j.0022-3506.2004.00263.x

23. Casey B. Beyond simple models of self-control to circuit-based accounts of adolescent behavior. Annu Rev Psychol (2015) 66(1):295-319. doi: 10.1146/ annurev-psych-010814-015156

24. Huang L, Krasikova D, Liu D. I can do it, so can you: the role of leader creative self-efficacy in facilitating follower creativity. Organ Behav Hum Decis Process (2016) 132:49-62. doi: 10.1016/j.obhdp.2015.12.002

25. Schwarzer R ed. Self-efficacy: thought control of action. New York, NY: Routledge (2014). doi: 10.4324/9781315800820

26. Schwarzer R, Antoniuk A, Gholami M. A brief intervention changing oral self-care, self-efficacy, and self-monitoring. Br J Health Psychol (2014) 20(1):56-67. doi: 10.1111/bjhp.12091

27. Lee J, Mendlinger S. Perceived self-efficacy and its effect on online learning acceptance and student satisfaction. J Serv Sci Manage (2011) 04(03):243-52. doi: 10.4236/jssm.2011.43029

28. Anderson E, Wojcik J, Winett R, Williams D. Social-cognitive determinants of physical activity: the influence of social support, self-efficacy, outcome expectations, and self-regulation among participants in a church-based health promotion study. Health Psychol (2006) 25(4):510-20. doi: 10.1037/ 0278-6133.25.4.510

29. Honicke T, Broadbent J. The influence of academic self-efficacy on academic performance: a systematic review. Educ Res Rev (2016) 17:63-84. doi: 10.1016/j.edurev.2015.11.002

30. Hirschi A, Jaensch V. Narcissism and career success: occupational selfefficacy and career engagement as mediators. Pers Individ Dif (2015) 77:205-8. doi: 10.1016/j.paid.2015.01.002

31. Bandura A. On the functional properties of perceived self-efficacy revisited. J Manage (2011) 38(1):9-44. doi: 10.1177/0149206311410606

32. Ein-Gar D. Committing under the shadow of tomorrow: self-control and commitment to future virtuous behaviors. J Consum Psychol (2015) 25(2):268-85. doi: 10.1016/j.jcps.2014.08.006

33. Miller E, Cohen J. An integrative theory of prefrontal cortex function. Annu Rev Neurosci (2001) 24(1):167-202. doi: 10.1146/annurev.neuro.24. 1.167

34. Cicchetti D, Cohen D. Developmental psychopathology. Hoboken, New Jersey: Wiley (2015). doi: 10.1002/9780470939390

35. Eisenberg N, Spinrad T. Emotion-related regulation: sharpening the definition. Child Dev (2004) 75(2):334-9. doi: 10.1111/j.1467-8624.2004.00674.x

36. Morrison R, Pidgeon, A.M. Cultivating resilience and self-control among university students: an experimental study. Univers J Psychol (2017) 5(1):1-7. doi: 10.13189/ujp.2017.050101

37. Cassidy S. Resilience building in students: the role of academic self-efficacy. Front Psychol (2015) 1781. doi: 10.3389/fpsyg.2015.01781

38. Keye M, Pidgeon A. Investigation of the relationship between resilience, mindfulness, and academic self-efficacy. Open J Soc Sci (2013) 01(06):1-4. doi: $10.4236 /$ jss. 2013.16001

39. Lightsey O. Resilience, meaning, and well-being. Couns Psychol (2006) 34(1):96-107. doi: 10.1177/0011000005282369

40. Artuch-Garde R, González-Torres M, de la Fuente J, Vera M, FernándezCabezas M, López-García M. Relationship between resilience and selfregulation: a study of Spanish youth at risk of social exclusion. Front Psychol (2017) 8. doi: 10.3389/fpsyg.2017.00612

41. Richardson G. The metatheory of resilience and resiliency. J Clin Psychol (2002) 58(3):307-21. doi: 10.1002/jclp.10020

42. Van Vliet K. Shame and resilience in adulthood: a grounded theory study. J Couns Psychol (2008) 55(2):233-45. doi: 10.1037/0022-0167.55.2.233

43. Schwarzer R, Warner LM. Perceived self-efficacy and its relationship to resilience. In: Prince-Embury A, Saklofske DH, editors. Resilience in children, adolescents, and adults: translating research into practice. New York: The Springer Series on Human Exceptionality, Springer (2013). p. 139-50.

44. Morrison B, Ruiz R. Self esteem. New York: Rosen Pub. (2012).

45. Lee Y, Cheng C, Lin S. A latent profile analysis of self-control and selfesteem and the grouping effect on adolescent quality of life across two consecutive years. Soc Indic Res (2013) 117(2):523-39. doi: 10.1007/ s11205-013-0360-5

46. Aryana M. Relationship between self-esteem and academic achievement amongst pre-university students. J Appl Sci (2010) 10(20):2474-7. doi: 10.3923/jas.2010.2474.2477

47. Trzesniewski K, Donnellan M, Moffitt T, Robins R, Poulton R, Caspi A. Low self-esteem during adolescence predicts poor health, criminal behavior, and limited economic prospects during adulthood. Dev Psychol (2006) 42(2):381-90. doi: 10.1037/0012-1649.42.2.381

48. Caprara G, Alessandri G, Barbaranelli C, Vecchione M. The longitudinal relations between self-esteem and affective self-regulatory efficacy. J Res Pers (2013) 47(6):859-70. doi: 10.1016/j.jrp.2013.08.011

49. Ryan M. The antidepressant effects of physical activity: mediating selfesteem and self-efficacy mechanisms. Psychol Health (2008) 23(3):279-307. doi: 10.1080/14768320601185502

50. Kanter RM. Confidence: how winning and losing streaks begin and end. New York, NY: Crown Publishing (2006).

51. Benetti C, Kambouropoulos N. Affect-regulated indirect effects of trait anxiety and trait resilience on self-esteem. Pers Individ Dif (2006) 41(2):34152. doi: 10.1016/j.paid.2006.01.015

52. Taylor A, MacKinnon D, Tein J. Tests of the three-path mediated effect. Organ Res Methods (2007) 11(2):241-69. doi: 10.1177/1094428107300344 
53. O'Rourke H, MacKinnon D. When the test of mediation is more powerful than the test of the total effect. Behav Res Methods (2014) 47(2):424-42. doi: 10.3758/s13428-014-0481-Z

54. American Psychiatric Association. Diagnostic and statistical manual of mental disorders, fifth edition. Washington, D.C.: American Psychiatric Association Publishing (2013). doi: 10.1176/appi.books.9780890425596

55. Xie DJ, Wang LG, Tao T, Fan CL, Gao WB. Validity and reliability of the Chinese version of the dual-mode of self-control scale for adolescents. Chin Ment Health J (2014) 9(5):386-91. doi: 10.1371/journal.pone.0115948

56. Connor KM, Davidson JRT. Development of a new resilience scale: the Connor-Davidson resilience scale (CD-RISC). Depress. Anxiety (2003) 18:76-82. doi: 10.1002/da.10113

57. Martínez-Martí ML, Ruch W. Character strengths predict resilience over and above positive affect, self-efficacy, optimism, social support, self-esteem, and life satisfaction. J Posit Psychol (2017) 12(2):110-9. doi: $10.1080 / 17439760.2016 .1163403$

58. Rosenberg M. Society and the adolescent self-image. Princeton, NJ: Princeton University Press (1965). doi: 10.1515/9781400876136

59. Bajaj B, Gupta R, Pande N. Self-esteem mediates the relationship between mindfulness and well-being. Pers Individ Dif (2016) 94:96-100. doi: 10.1016/j.paid.2016.01.020

60. Wang YJ, Dou K, Liu Y. Revision of the scale of regulatory emotional selfefficacy [in Chinese]. J. Guangzhou Univ. (2013) 12:41-6.

61. Caprara G, Giunta L, Eisenberg N, Gerbino M, Pastorelli C, Tramontano C. Assessing regulatory emotional self-efficacy in three countries. Psychol Assess (2008) 20(3):227. doi: 10.1037/1040-3590.20.3.227

62. Anderson J, Gerbing D. Structural equation modeling in practice: a review and recommended two-step approach. Psychol Bull (1988) 103(3):411-23. doi: 10.1037/0033-2909.103.3.411

63. Little T, Cunningham W, Shahar G, Widaman K. To parcel or not to parcel: exploring the question, weighing the merits. Struct Equ Model (2002) 9(2):151-73. doi: 10.1207/S15328007SEM0902_1

64. Hu L, Bentler P. Cutoff criteria for fit indexes in covariance structure analysis: conventional criteria versus new alternatives. Struct Equ Model (1999) 6(1):1-55. doi: 10.1080/10705519909540118

65. Siedlecki, KL, Salthouse TA, Oishi S, Jeswani S. The relationship between social support and subjective well-being across age. Social Indicators Research (2014) 117(2):561. doi: 10.1007/s11205-013-0361-4

66. Akaike H. Factor analysis and AIC. Psychometrika (1987) 52(3):318-32. doi: 10.1007/BF02294359
67. Browne MW, Cudeck R. Alternative ways of assessing model fit. Newbury Park, CA: Sage (1993).

68. MacKinnon D, Lockwood C, Williams J. Confidence limits for the indirect effect: distribution of the product and resampling methods. Multivariate Behav Res (2004) 39(1):99-128. doi: 10.1207/s15327906mbr3901_4

69. Byrne B. Structural equation modeling with Amos: basic concepts, applications and programming. New Jersey: Lawrence Erlbaum Associates (2001).

70. Arbuckle JL. AMOS 5.0 update to the AMOS user's guide. Chicago, IL: Smallwaters (2003).

71. Lee T, Cheung C, Kwong W. Resilience as a positive youth development construct: a conceptual review. Sci World J (2012) 2012:1-9. doi: $10.1100 / 2012 / 390450$

72. Ahangar R. A study of resilience in relation to personality, cognitive styles, and decision making style of management students. Afr J Bus Manage (2010) 4(6):953-61.

73. Tras Z, Arslan C, Hamarta E. An examination of resilience in university students in terms of self-esteem and social self-efficacy. Int J Acad Res (2013) 5(3):325-30. doi: 10.7813/2075-4124.2013/5-3/B.49

74. Liu Y, Wang Z, Zhou C, Li T. Affect and self-esteem as mediators between trait resilience and psychological adjustment. Pers Individ Dif (2014) 66:92-7. doi: 10.1016/j.paid.2014.03.023

75. Amen D, Trujillo M, Keator D, Taylor D, Willeumier K, Meysami S, et al. Gender-based cerebral perfusion differences in 46,034 functional neuroimaging scans. J Alzheimers Dis (2017) 60(2):605-14. doi: 10.3233/JAD-170432

76. Ross S, Peselow E. Co-occurring psychotic and addictive disorders: neurobiology and diagnosis. Clin Neuropharmacol (2012) 35(5):235-43. doi: 10.1097/WNF.0b013e318261e193

77. Baigent M. Managing patients with dual diagnosis in psychiatric practice. Curr Opin Psychiatry (2012) 25(3):201-5. doi: 10.1097/YCO.0b013e3283523d3d

Conflict of Interest Statement: The authors declare that the research was conducted in the absence of any commercial or financial relationships that could be construed as a potential conflict of interest.

Copyright (C) 2019 Yang, Zhou, Cao, Xia and An. This is an open-access article distributed under the terms of the Creative Commons Attribution License (CC $B Y)$. The use, distribution or reproduction in other forums is permitted, provided the original author(s) and the copyright owner(s) are credited and that the original publication in this journal is cited, in accordance with accepted academic practice. No use, distribution or reproduction is permitted which does not comply with these terms. 